\title{
Morphology Effect of Silver Nanostructures on the Performance of a P3HT:Graphene:AgNs-Based Active Layer Obtained via Dip Coating
}

\author{
Alí Gómez-Acosta, ${ }^{1}$ Zaira Barquera-Bibiano, ${ }^{2}$ Edgar J. López-Naranjo, ${ }^{3}$ \\ José Luis Reyes-Araiza, ${ }^{1}$ Gerardo Torres-Delgado, ${ }^{2}$ Oracio Barbosa-García, ${ }^{4}$ \\ Eric M. Rivera-Muñoz, ${ }^{5}$ Rodrigo Velázquez-Castillo, ${ }^{6}$ and Alejandro Manzano-Ramírez ${ }^{2}$ \\ ${ }^{1}$ Facultad de Ingeniería, Universidad Autónoma de Querétaro, Cerro de Las Campanas, s/n, Las Campanas, \\ 76010 Querétaro, QRO, Mexico \\ ${ }^{2}$ CINVESTAV-IPN Unidad Querétaro, 76230 Querétaro, QRO, Mexico \\ ${ }^{3}$ Departamento de Ingeniería de Proyectos, Centro Universitario de Ciencias Exactas e Ingenierías, \\ Universidad de Guadalajara, 44430 Guadalajara, JAL, Mexico \\ ${ }^{4}$ Centro de Investigaciones en Óptica, A.P. 1-948, 37000 León, GTO, Mexico \\ ${ }^{5}$ Centro de Física Aplicada y Tecnología Avanzada, UNAM, A.P. 1-1010, 76000 Querétaro, QRO, Mexico \\ ${ }^{6}$ División de Investigación y Posgrado, Facultad de Ingeniería, Universidad Autónoma de Querétaro, \\ Cerro de Las Campanas, s/n, 76010 Querétaro, QRO, Mexico
}

Correspondence should be addressed to Alejandro Manzano-Ramírez; amanzano@cinvestav.mx

Received 23 June 2016; Revised 29 July 2016; Accepted 21 August 2016

Academic Editor: Shu Seki

Copyright (C) 2016 Alí Gómez-Acosta et al. This is an open access article distributed under the Creative Commons Attribution License, which permits unrestricted use, distribution, and reproduction in any medium, provided the original work is properly cited.

We report the effect of the use of different silver nanostructures (AgNs) layers deposited via dip coating onto a poly(3hexylthiophene) (P3HT) and solution processable functionalized graphene (SPFGraphene) composite film intended to be used as active layer in $\mathrm{BHJ}$ devices. SPFGraphene was added to $\mathrm{P} 3 \mathrm{HT}$ in a ratio of $1.5 \mathrm{wt} \%$. The best results were achieved when a layer of silver nano-pseudospheres (AgNPSs) obtained after 10 immersion cycles was used as coating; in this case the highest light trapping and efficiency percent $(\eta=0.23 \%)$ were achieved. This means an increase of $\sim 11.3 \%$ in comparison with the efficiency of the noncoated P3HT:SPFGraphene composite. Results also indicate that graphene was successfully functionalized in order to obtain appropriate dispersion in $\mathrm{P} 3 \mathrm{HT}$ and that such conjugated polymer remained unaltered after the addition of SPFGraphene. Finally, it can be concluded that the electrical properties of the as-synthesized films are dependent on the shape and concentration of the AgNs deposited via dip coating.

\section{Introduction}

Organic solar cells (OSCs) have become an attractive and promising technology to gather solar energy. In the bulk heterojunction $(\mathrm{BHJ})$ organic solar cells, the conformation of the active layer is important to achieve high efficiencies [1]; as a result semiconducting or metallic nanostructures (Ns) incorporated into the active layer have shown to be the most efficient light trapping strategy since this offers local surface plasmon resonance (SPR). Among the metallic Ns, AgNs and
AuNs are reported to be the most promising for light trapping, since they have intense plasmonic resonances that lie within the UV-vis region of the solar spectrum $[2,3]$. In recent years, several $\mathrm{BHJ}$ devices have been made using polymer composites blends, being the combination of poly(3hexylthiophene) (P3HT) with $[6,6]$-phenyl- $\mathrm{C}_{61}$-butyric acid methyl ester (PCBM) the most widely used. However, the efficiency of the $\mathrm{BHJ}$ devices using such polymer blend is limited by inefficient hopping charge transport. One way to overcome this limitation consists in replacing PCBM with 
nanomaterials such as graphene and metallic nanostructures (MNNs) [3-5]. The incorporation of graphene in the active layer provides additional paths for the electrons transport, suppressing charge recombination [6]. On the other hand, MNNs enhance optical absorption properties. The properties of MNNs are highly dependent on size and shape; thus, the synthesis of tailored shapes and sizes becomes increasingly important [7]. Therefore, as the morphology of the MNNs changes, the morphology of the blend used as active layer will also change, affecting the performance of the $\mathrm{BHJ}$ device.

Regarding solution-processed $\mathrm{BHJ}$ devices, spin coating method is considered as the most reliable and reproducible process. However, the spin coating method shows several negative issues related to its application in mass production. This method is only suitable for a limited substrate size, with large materials waste and an incompatibility with roll-to-roll processing. Thus, for low cost production and commercialization of BHJ devices, a high throughput, continuous process, and large area devices on flexible substrates are necessary. In this regard, different deposition methods have been tested including dip coating, spray coating, and screen printing. Dip coating process is a commonly used method for conventional dyeing and can provide easy and fast deposition of polymer films over a large area. This method may be suitable for largescale production of $\mathrm{BHJ}$ devices. The formation of dip-coated films is a slow natural drying process, which offers the opportunity to develop an active layer morphology and obtain specific film properties $[8,9]$.

Thus, in this paper, we present a detailed research of the photovoltaic performance of P3HT:Graphene:silver nanostructures- (AgNs-) based active layers produced via dip coating for $\mathrm{BHJ}$ devices along with the effect of the morphology of AgNs on the active layer performance.

\section{Materials and Methods}

2.1. Materials. The materials used were the following: silver nitrate $\left(\mathrm{AgNO}_{3}, 99.99 \%\right.$, Sigma-Aldrich), polyvinyl pyrrolidone (PVP, MW = 40,000, Sigma-Aldrich), ethylene glycol (EG, anhydrous, 99.8\%, Sigma-Aldrich), acetone (AC, 99.7\%, Fermont), deionized water (DW, Hycel), ethanol (ET, 99.7\%, Golden Bell), graphite flakes (Sigma-Aldrich), N,N-dimethylformamide (DMF, anhydrous, 99.8\%, SigmaAldrich), phenyl isocyanate (PI, 99\%, Sigma-Aldrich), chloroform (CF, anhydrous, 99\%, Sigma-Aldrich), poly(3-hexylthiophene-2,5-diyl) (P3HT, regioregular, Sigma-Aldrich), 1,2dichlorobenzene (DCB, anhydrous, 99\%, Sigma-Aldrich), isopropyl alcohol (IA, 70\% dispersion in $\mathrm{H}_{2} \mathrm{O}$ ), potassium permanganate (PP, 99\%, Sigma-Aldrich), sulfuric acid (SA, $30 \%$, Jalmek), hydrochloric acid (HA, 37\%, Vetec), hydrogen peroxide (HP, 30\%, J. Baker), silicon (100) wafer p-type, and boron doped $(60 \mathrm{~mm} \times 200 \mu \mathrm{m}$, thickness $350-450 \mu \mathrm{m}$, Wafer World). All chemicals were used as received without any further purification.

\subsection{Synthesis}

2.2.1. Synthesis of AgNs. Silver nanostructures were synthesized by a polyol method. For a typical synthesis, $5 \mathrm{~mL}$ of pure
EG and $0.160 \mathrm{AgNO}_{3}$ dissolved in $3 \mathrm{~mL}$ of EG were refluxed in a three-necked flask at $160^{\circ} \mathrm{C}$ under vigorous stirring $(450 \mathrm{rpm})$. Then a solution of $0.156 \mathrm{~g}$ PVP dissolved in $3 \mathrm{~mL}$ of EG was injected dropwise ( $\sim 5 \mathrm{~min}$ for injection). As the first drops of PVP solution were added, the mixture turned yellow. With continuous addition, it became gradually turbid for a final gray color. The $\mathrm{PVP} / \mathrm{AgNO}_{3} / \mathrm{EG}$ solution was refluxed at $160^{\circ} \mathrm{C}$ during $60 \mathrm{~min}$, after which the reaction was stopped, allowing the product to cool to room temperature. Finally, in order to separate polymer from AgNs, the solution was diluted three times with AC and three times with DW (both in a ratio of $1: 2.5$ ) and centrifuged after each dilution at $4000 \mathrm{rpm}$ during $7 \mathrm{~min}[10]$.

2.2.2. Synthesis of Solution Processable Functionalized Graphene (SPFGraphene). Graphene oxide (GO) was prepared by a variation of the Hummers method using synthetic graphite flakes as starting material. First, graphite $(1 \mathrm{~g})$ and concentrated SA $(23 \mathrm{~mL})$ were added into a $500 \mathrm{~mL}$ flask kept at $5^{\circ} \mathrm{C}$ in an ice bath under continuous stirring for $5 \mathrm{~min}$. Then, PP ( $3 \mathrm{~g}$ ) was slowly added into the flask to prevent strong reaction at local points. The reaction mixture was maintained at $5^{\circ} \mathrm{C}$ for $5 \mathrm{~min}$ and then the reaction temperature was slowly raised to $40^{\circ} \mathrm{C}$ and kept another $2 \mathrm{~h}$ with vigorous stirring. DW $(46 \mathrm{~mL})$ was added to the suspension, and as consequence of the hydration heat, the temperature increased to $98^{\circ} \mathrm{C}$ and was maintained for $15 \mathrm{~min}$ with stirring. The reaction was then finished adding DW $(140 \mathrm{~mL})$ and $\mathrm{HP}(30 \% \mathrm{v} / \mathrm{v}, 10 \mathrm{~mL})$. The resulting product had a brown/yellowish color and was separated by vacuum filtration from the solution. The resulting GO powders were washed with diluted HA $(1 \mathrm{M}, 10 \mathrm{~mL})$ solution and warm DW $\left(90^{\circ} \mathrm{C}\right)$ to remove the remnant $\mathrm{Mn}$ ions and acid, respectively, and later dried in air at $60^{\circ} \mathrm{C}$ into an oven during $24 \mathrm{~h}$ [11]. The functionalization process of the GO was briefly as follows: graphene oxide $(200 \mathrm{mg}$ ) was suspended in anhydrous DMF $(20 \mathrm{~mL})$ and treated with PI (20 g) for a week. Then the reaction mixture was added dropwise into DCB and centrifuged at $1000 \mathrm{rpm}$ for $10 \mathrm{~min}$. The upper solution was dropped into CF and centrifuged at 10,00 rpm to collect the deposit at the bottom [12].

2.3. Active Layer Elaboration. Regioregular P3HT was dissolved in DCB $(15 \mathrm{mg} / \mathrm{mL})$ and stirred for $1 \mathrm{~h}$ at room temperature. SPFGraphene was sonicated during $1 \mathrm{~h}$ at $25^{\circ} \mathrm{C}$. Then, SPFGraphene was added to the P3HT solution (SPFGraphene:P3HT, $1.5 \mathrm{wt} \%$ ) and mixed during $15 \mathrm{~min}$ at $60^{\circ} \mathrm{C}$. Active layer of P3HT:SPFGraphene was obtained via dip coating. First, the substrate (silicon wafer) was cleaned in an ultrasonic bath with detergent, $\mathrm{AC}$, and IA for three cycles. Then, the substrate was upright fully soaked in the P3HT:SPFGraphene solution during $40 \pm 2 \mathrm{~s}$ and removed from the solution with a lifting rate of $5.36 \mathrm{~cm} / \mathrm{min}$. P3HT:SPFGraphene films were dried during $4 \mathrm{~min}$ before being thermally treated (TT) and then immersed into different nanostructures dispersions according to Table 1. Once the film was removed from the dispersion and the solvent evaporated, the nonvolatile nanostructures remained on 
TABLE 1: Processing conditions to obtain layers of nanostructures.

\begin{tabular}{lccc}
\hline Sample & $\begin{array}{c}\text { Nanostructures } \\
\text { morphology }\end{array}$ & Immersion cycles & TT (at 110 $\mathrm{C}$ ) \\
\hline 1 & - & - & $10 \mathrm{~min}$ \\
2 & $\begin{array}{c}\text { Nano- } \\
\text { pseudospheres } \\
\text { Nano- }\end{array}$ & 10 & $10 \mathrm{~min}$ \\
3 & $\begin{array}{c}\text { pseudospheres } \\
\text { Nanowires }\end{array}$ & 20 & $10 \mathrm{~min}$ \\
4 & Nanowires & 10 & $10 \mathrm{~min}$ \\
5 & & 20 & $10 \mathrm{~min}$ \\
\hline
\end{tabular}

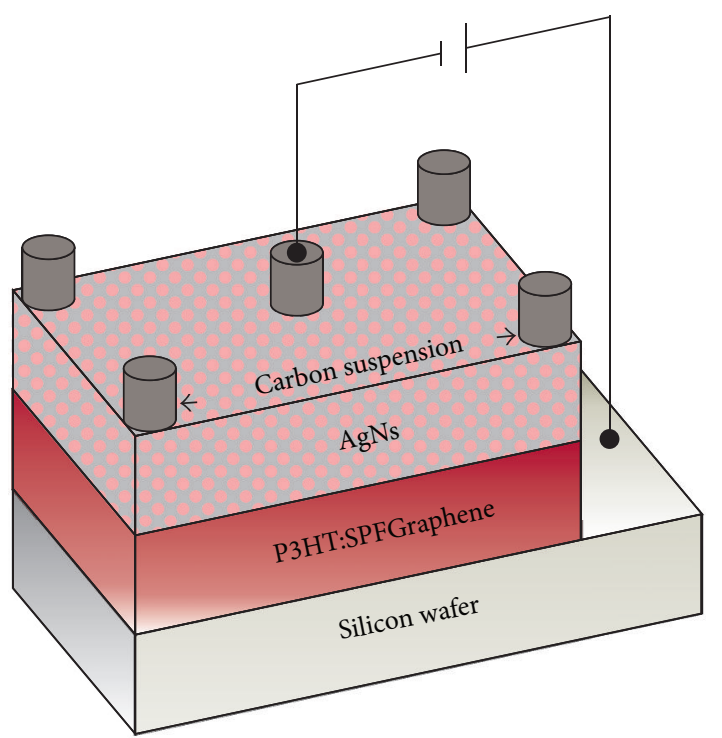

Figure 1: Schematics of BHJ device used in the experimentation.

the substrate forming a thin layer. Additionally, the device configuration is shown on Figure 1.

2.4. Characterization. Optical properties: FTIR spectroscopy was conducted on a PerkinElmer FTIR system spectrum GX. The scans were run at a resolution of $4 \mathrm{~cm}^{-1}$. For each sample, 24 scans were recorded from 4000 to $500 \mathrm{~cm}^{-1}$. Transmission technique was used for data collection. A Horiba, Evolution HR device was used for acquiring Raman spectra of the irradiated samples. The wavelength of the excitation laser was $633 \mathrm{~nm}$, originated from a red laser. The laser power was kept at $20 \mathrm{~mW}$. The Raman spectra were acquired by a $50 \mathrm{x}$ objective with a spot size of $2 \mu \mathrm{m}$. Electrical tests were performed using a Keithley 4200-SCS semiconductor characterization system with $100 \mathrm{~mW} / \mathrm{cm}^{2}$ irradiance.

AgNs characterization: particle size was determined using a Zetasizer Nano series, Nano-ZS, Malvem, using ethanol as dispersant agent. Morphologies were characterized using scanning electron microscopy (SEM) employing a Philips XL 30 ESEM device.

Electrical properties: fill factor (FF) was determined according to $\mathrm{FF}=\left(V_{\max } * J_{\max }\right) /\left(V_{\mathrm{oc}} * J_{\mathrm{sc}}\right)$, where $V_{\max }$ and $J_{\max }$ are the voltage and the current density in the maximum power point of the $J-V$ curve in the fourth quadrant. Current density-voltage $(J-V)$ of the photovoltaic devices was measured using a Keithley 4200-SCS source measure unit and a halogen lamp calibrated with an Oriel reference cell at $100 \mathrm{~mW} / \mathrm{cm}^{2}$.

\section{Results and Discussion}

According to particle size characterization performed using a Zetasizer Nano series, AgNPSs show a dynamic diameter of $342.53 \pm 112.15 \mathrm{~nm}$ and a polydispersity index (PDI) of 0.0963. Regarding silver nanowires (AgNWs) dynamic diameter was of $370.43 \pm 151.6 \mathrm{~nm}$ and PDI was of 0.135 . In both cases, reported values correspond to the mean value of three samples. PDI values indicate that AgNPSs are well dispersed; therefore better $\eta$ are expected for films using this type of structures. On the other hand, typical SEM images of the as-synthesized silver nanostructures are shown on Figure 2.

Figure 3 shows Raman spectra of the SPFG, P3HT, and P3HT:SPFGraphene films. As it was expected, characteristic peaks of graphene, at $\sim 1340-1360 \mathrm{~cm}^{-1}$ (D band), $\sim 1575-$ $1604 \mathrm{~cm}^{-1}$ (G band), and $\sim 2650-2695 \mathrm{~cm}^{-1}$ (2D band), were observed (Figure 3(a)). Characteristic peaks of P3HT, at $1445 \mathrm{~cm}^{-1}$ and $\sim 1381 \mathrm{~cm}^{-1}$, corresponding, respectively, to symmetric $\mathrm{C}=\mathrm{C}$ stretch mode and the $\mathrm{C}-\mathrm{C}$ skeletal stretching mode are shown on Figure 3(b). Finally, Figure 3(c), corresponding to the P3HT:SPFGraphene nanocomposite, showed the presence of the two main modes Raman peaks of $\mathrm{P} 3 \mathrm{HT}$, proving that chemical structure of $\mathrm{P} 3 \mathrm{HT}$ was not modified and remains unaltered after addition of SPFGraphene. Regarding graphene, the absence of $\mathrm{D}$ band indicates the presence of a well-ordered material. It also can be concluded that graphene is present as reduced-graphene due to annealing treatment at $110^{\circ} \mathrm{C}$. On the other hand, the $\mathrm{G}$ band of graphene was shifted to $1646 \mathrm{~cm}^{-1}$ due to the charge transfer between the donor and the acceptor of electrons (i.e., P3HT and SPFGraphene) $[13,14]$.

FTIR spectra of GO and SPFGraphene are depicted on Figure 4. The main absorption bands in the FTIR spectrum of GO correspond to $\mathrm{C}=\mathrm{O}$ at $1732 \mathrm{~cm}^{-1}$ and $\mathrm{O}-\mathrm{H}$ at $3391 \mathrm{~cm}^{-1}$. The functionalization of $\mathrm{GO}$ leads to the derivatization of carboxyl groups via formation of amides. The band at $1600 \mathrm{~cm}^{-1}$ can be assigned to an amide carbonyl-stretching mode (amide I) and the band at $1530 \mathrm{~cm}^{-1}$ could correspond to the coupling of the $\mathrm{C}-\mathrm{N}$ stretching vibration with the CHN deformation vibration (amide II). It is also important to remark that the spectra of SPFGraphene do not show typical bands corresponding to isocyanate group $\left(\sim 2263 \mathrm{~cm}^{-1}\right)$, indicating that the treatment of GO with phenyl isocyanate results in chemical reactions and not just absorption/intercalation of the organic isocyanate [15].

The $J-V$ properties of the P3HT:SPFGraphene:AgNs active layer are summarized in Table 2. It can be observed that there is a direct proportion between $J_{\text {sc }}$ and $\eta$. Additionally, it is known that $\eta$ is strongly dependent on the contact area used during the experimentation. In addition metal Ns embedded in a dielectric matrix strongly interact with light at their dipole surface plasmon frequency due to the excitation of a collective electron motion (known as plasmon) inside the 
TABLE 2: Photovoltaic parameters of the P3HT:SPFGraphene:AgNs active layer.

\begin{tabular}{|c|c|c|c|c|c|c|}
\hline Sample & $V_{\mathrm{oc}}(\mathrm{V})$ & $J_{\mathrm{sc}}\left(\mathrm{mA} / \mathrm{cm}^{2}\right)$ & $V_{\max }(\mathrm{V})$ & $J_{\max }\left(\mathrm{mA} / \mathrm{cm}^{2}\right)$ & FF & $\eta(\%)$ \\
\hline 1 & 0.530 & 0.987 & 0.340 & 0.600 & 0.390 & 0.204 \\
\hline 2 & 0.548 & 1.000 & 0.379 & 0.607 & 0.418 & 0.230 \\
\hline 3 & 0.467 & 0.975 & 0.362 & 0.594 & 0.473 & 0.215 \\
\hline 4 & 0.525 & 0.971 & 0.347 & 0.593 & 0.404 & 0.206 \\
\hline 5 & 0.527 & 0.980 & 0.348 & 0.601 & 0.405 & 0.209 \\
\hline
\end{tabular}

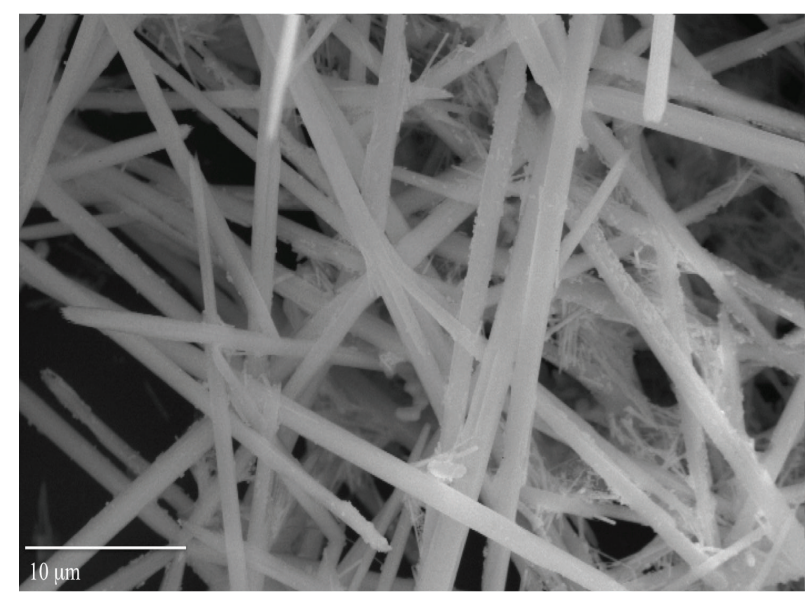

(a)

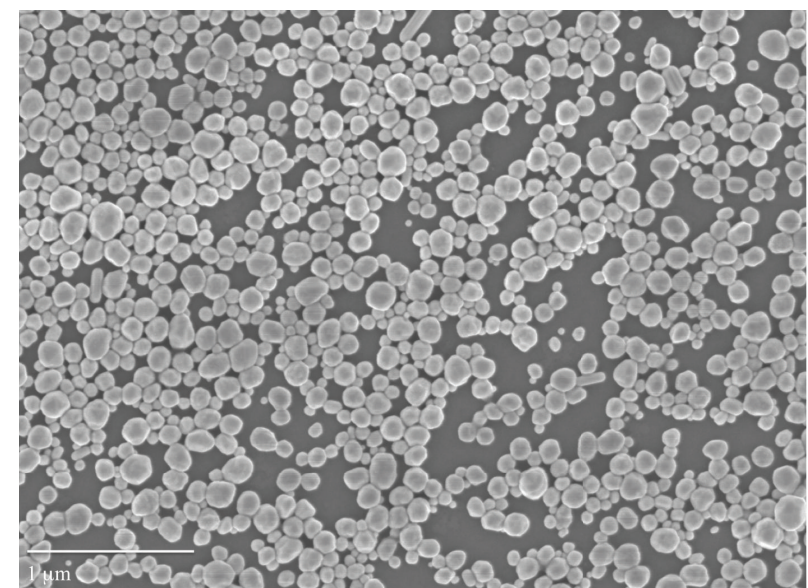

(b)

Figure 2: SEM images of (a) AgNWs and (b) AgNPSs.

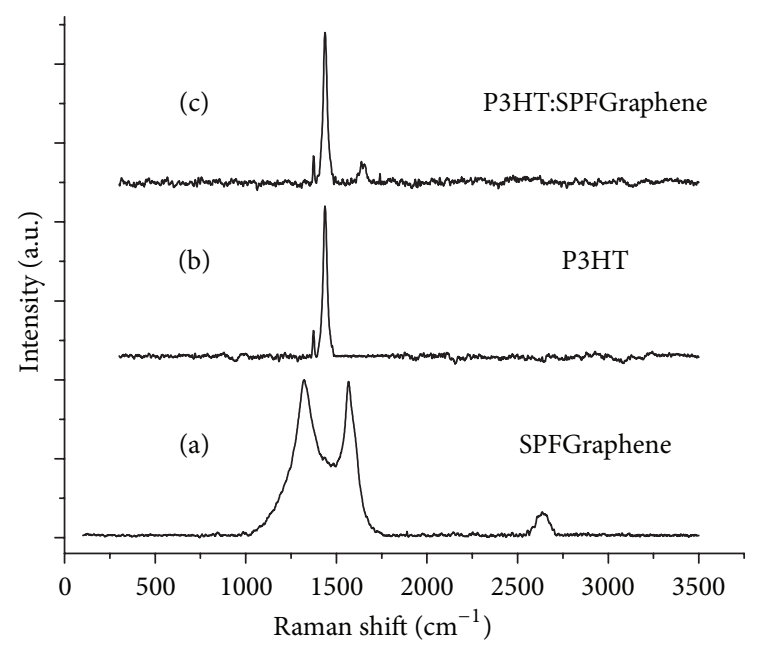

Figure 3: Raman spectra of (a) SPFGraphene, (b) P3HT, and (c) P3HT:SPFGraphene.

metal particle. Hence the surface confines the conduction electrons inside the particles and a surface plasmon resonance (SPR) is set up, which depends on the shape, size, and distribution of the metal Ns. On Figure $5 \mathrm{UV}$-vis absorbance spectra of the P3HT:SPFGraphene:AgNs active layer are presented; in this figure, it can be noted that sample 2 shows the highest optical absorption value which can be attributed to a higher localized surface plasmon resonance as well as efficient

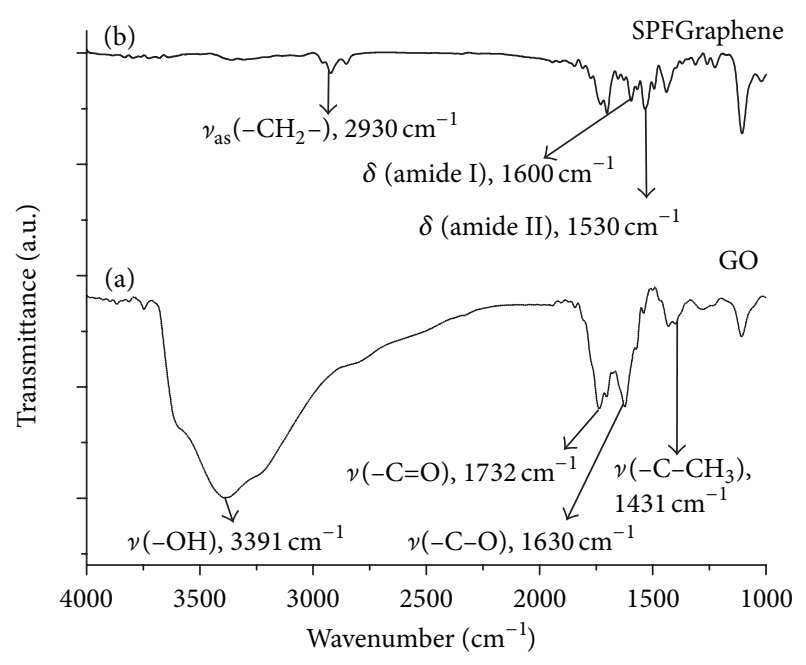

FIGURE 4: FTIR spectra of (a) GO and (b) SPFGraphene.

light scattering from such AgNs [4]. Hence, in the present work and under the experimental conditions, sample 2 corresponds to the optimum film, covered with a AgNPSs layer formed after 10 immersion cycles. Thus, it is clearly confirmed that the electrical behavior of the as-synthesized films is dependent on the shape, size, and distribution of the AgNs (either nanowires or nano-pseudospheres) as it may be observed for sample 2. In addition, it has been even reported 


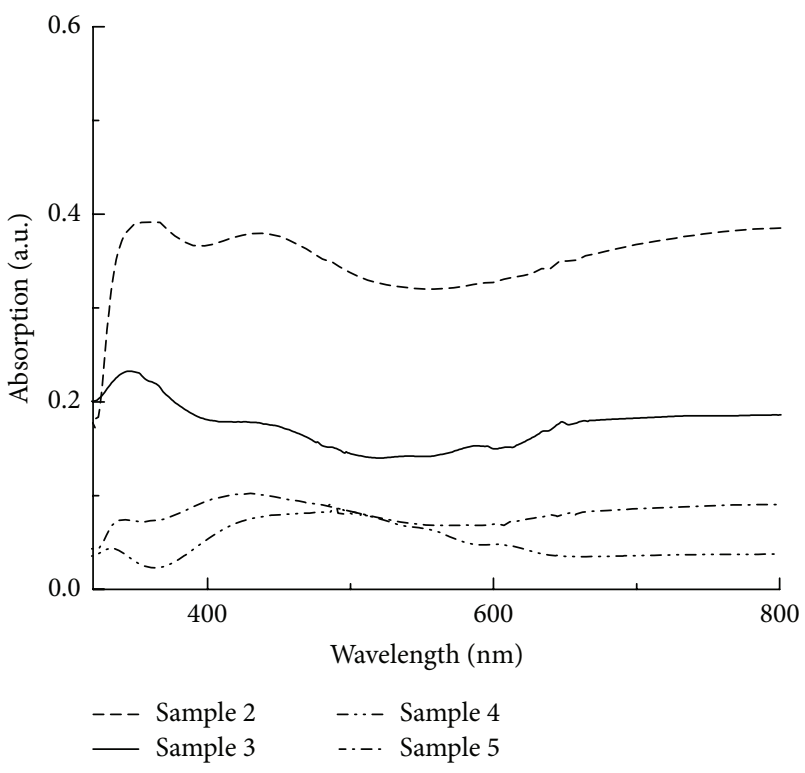

Figure 5: UV-vis absorbance spectra of the P3HT:SPFGraphene:AgNs active layer.

that spin coating produces more easily higher-quality films compared to dip coating (i.e., more homogeneous films) [16]. In the present work, it is important to remark that the photovoltaic performance of the P3HT:SPFGraphene and P3HT:SPFGraphene:AgNs active layers obtained via dip coating was superior to that reported by Bkakri et al. [14] who tested the performance of P3HT/Au and P3HT:Graphene/Au composites obtained by spin coating, which means that it is possible to use such low cost deposition production technique to obtain competitive films to be used as active layer.

\section{Conclusions}

In summary, our results indicate that the presence of AgNs applied onto P3HT:SPFGraphene films as an external coating improves the electrical performance of such composites. The morphology of AgNs is closely related to the electrical properties improvement that can be achieved. Finally, our results indicate that it is possible to obtain via dip coating films with a well surface plasmon resonance (SPR).

\section{Competing Interests}

The authors declare that there is no conflict of interests regarding the publication of this paper.

\section{Acknowledgments}

The authors gratefully thank José Eleazar Urbina-Sánchez and Cyntia Ivett Zúñiga-Romero at CINVESTAV for the technical support during this work.

\section{References}

[1] N. Kalfagiannis, P. G. Karagiannidis, C. Pitsalidis et al., "Plasmonic silver nanoparticles for improved organic solar cells," Solar Energy Materials and Solar Cells, vol. 104, pp. 165-174, 2012.

[2] J. R. Cole and N. J. Halas, "Optimized plasmonic nanoparticle distributions for solar spectrum harvesting," Applied Physics Letters, vol. 89, no. 15, Article ID 153120, 2006.

[3] Q. Liu, Z. Liu, X. Zhang et al., "Polymer photovoltaic cells based on solytion-processable graphene and P3HT," Advanced Functional Materials, vol. 19, no. 6, pp. 894-904, 2009.

[4] S. R. Gollu, R. Sharma, G. Srinivas, S. Kundu, and D. Gupta, "Incorporation of silver and gold nanostructures for performance improvement in P3HT: PCBM inverted solar cell with $\mathrm{rGO} / \mathrm{ZnO}$ nanocomposite as an electron transport layer," Organic Electronics, vol. 29, pp. 79-87, 2016.

[5] X.-H. Liu, L.-X. Hou, J.-F. Wang et al., "Plasmonic-enhanced polymer solar cells with high efficiency by addition of silver nanoparticles of different sizes in different layers," Solar Energy, vol. 110, pp. 627-635, 2014.

[6] Z. Liu, D. He, Y. Wang, H. Wu, and J. Wang, "Graphene doping of P3HT:PCBM photovoltaic devices," Synthetic Metals, vol. 160, no. 9-10, pp. 1036-1039, 2010.

[7] X. K. Meng, S. C. Tang, and S. Vongehr, "A review on diverse silver nanostructures," Journal of Materials Science and Technology, vol. 26, no. 6, pp. 487-522, 2010.

[8] Z. Hu, J. Zhang, S. Xiong, and Y. Zhao, "Performance of polymer solar cells fabricated by dip coating process," Solar Energy Materials and Solar Cells, vol. 99, pp. 221-225, 2012.

[9] Y. Liang, Z. Xu, J. Xia et al., "For the bright future-bulk heterojunction polymer solar cells with power conversion efficiency of 7.4\%," Advanced Materials, vol. 22, no. 20, pp. E135-E138, 2010.

[10] A. Gómez-Acosta, A. Manzano-Ramírez, E. J. López-Naranjo, L. M. Apatiga, R. Herrera-Basurto, and E. M. Rivera-Muñoz, "Silver nanostructure dependence on the stirring-time in a high-yield polyol synthesis using a short-chain PVP," Materials Letters, vol. 138, pp. 167-170, 2015.

[11] J. Guerrero-Contreras and F. Caballero-Briones, "Graphene oxide powders with different oxidation degree, prepared by synthesis variations of the Hummers method," Materials Chemistry and Physics, vol. 153, pp. 209-220, 2015.

[12] J. Wang, Y. Wang, D. He et al., "Composition and annealing effects in solution-processable functionalized graphene oxide/ P3HT based solar cells," Synthetic Metals, vol. 160, no. 23-24, pp. 2494-2500, 2010.

[13] R. Bkakri, O. E. Kusmartseva, F. V. Kusmartsev, M. Song, and A. Bouazizi, "Degree of phase separation effects on the charge transfer properties of P3HT:Graphene nanocomposites," Journal of Luminescence, vol. 161, pp. 264-270, 2015.

[14] R. Bkakri, N. Chehata, A. Ltaief et al., "Effects of the graphene content on the conversion efficiency of P3HT:graphene based organic solar cells," Journal of Physics and Chemistry of Solids, vol. 85, pp. 206-211, 2015.

[15] D. Romero-Borja, J.-L. Maldonado, O. Barbosa-García et al., "Polymer solar cells based on P3HT:PC ${ }_{71}$ BM doped at different concentrations of isocyanate-treated graphene," Synthetic Metals, vol. 200, pp. 91-98, 2015.

[16] K. Naito, N. Yoshinaga, and Y. Akasaka, "Material- and processeffects on homogeneity and electric properties of transparent conducting films composed of hydrazine-reduced graphene oxide and/or silver nanowire," Synthetic Metals, vol. 215, pp. 243-250, 2016. 

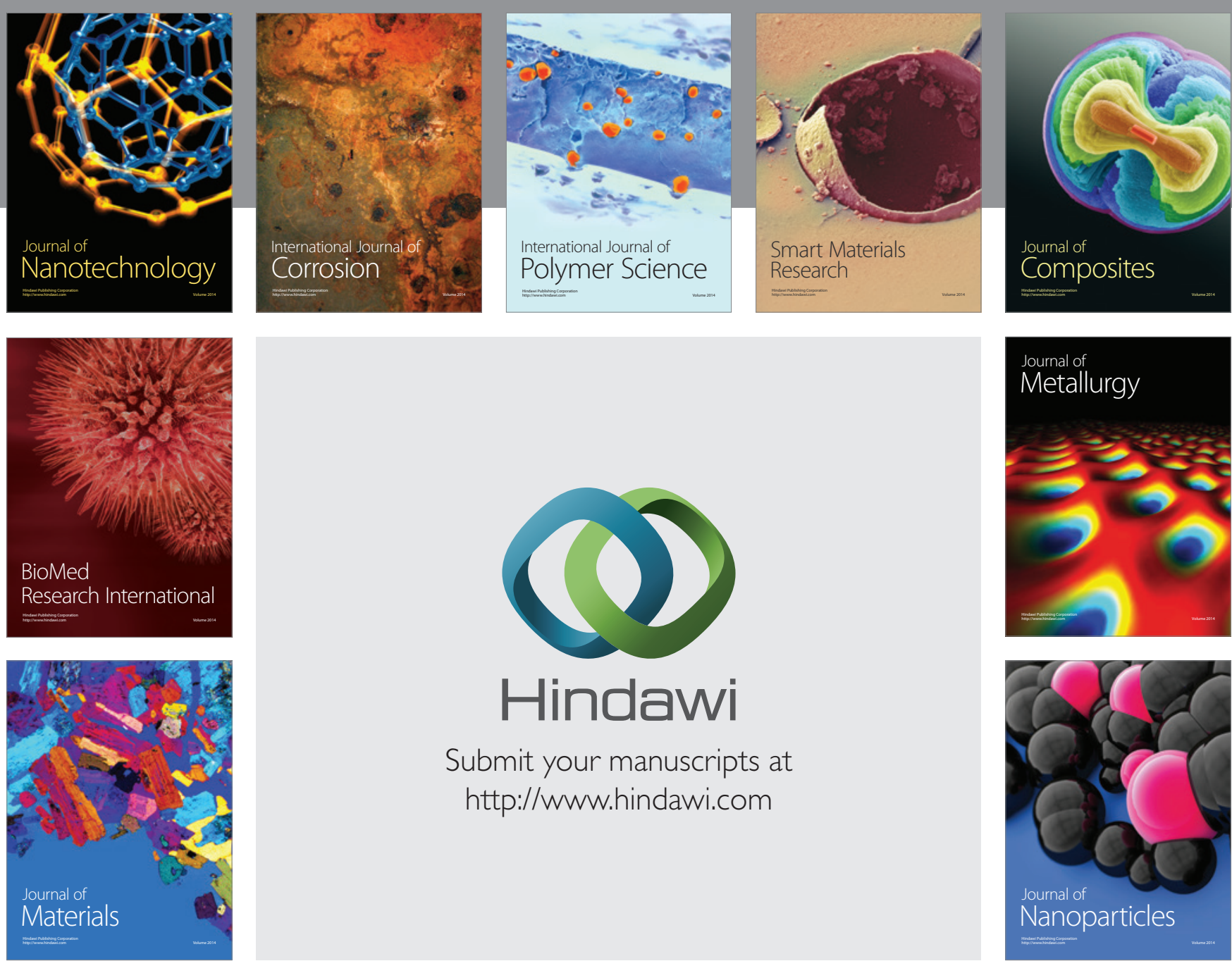

\section{Hindawi}

Submit your manuscripts at

http://www.hindawi.com

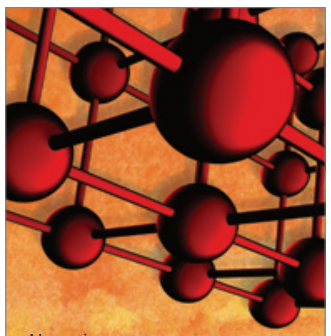

Materials Science and Engineering
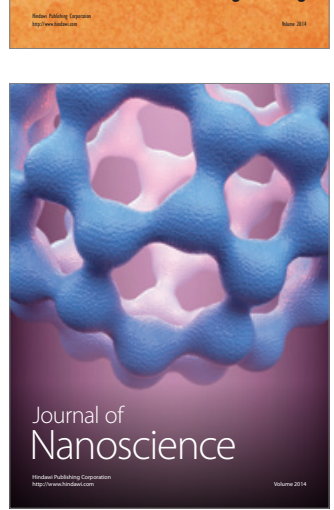
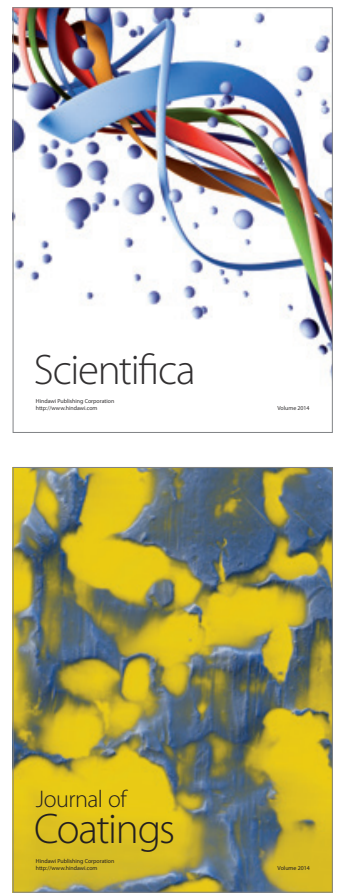
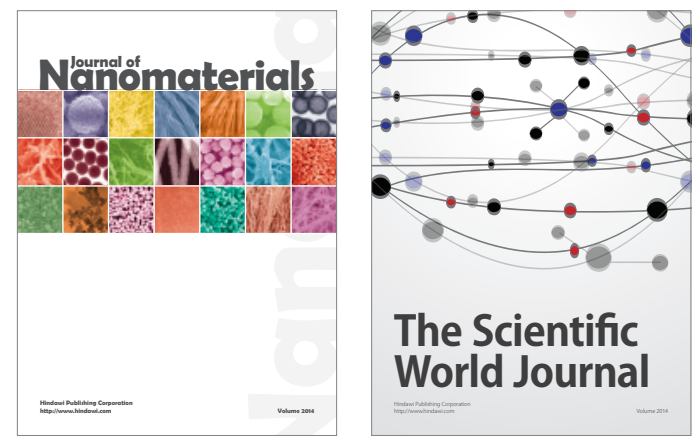

The Scientific World Journal
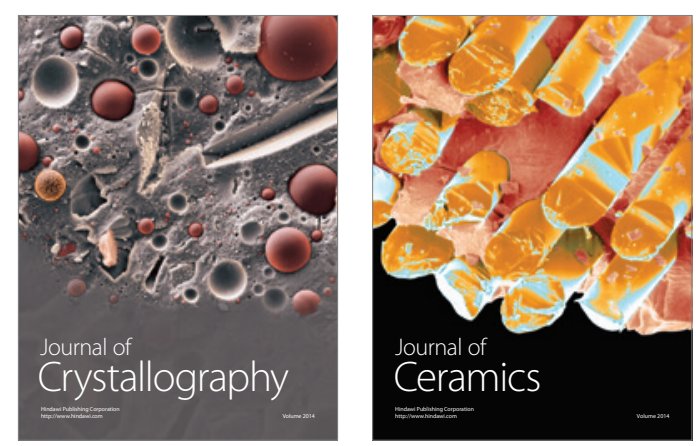
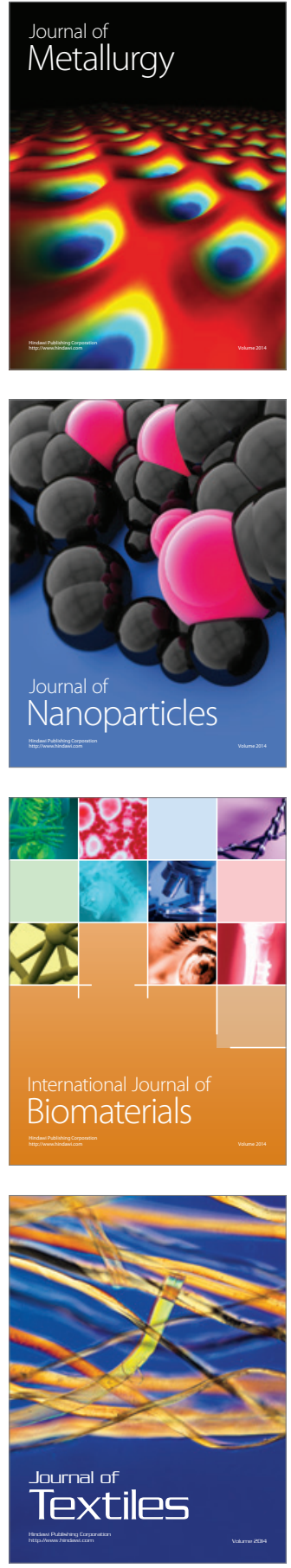